\title{
Correction to: Modeling outcomes of soccer matches
}

\section{Alkeos Tsokos $^{1}$ (D) Santhosh Narayanan ${ }^{2}$ - loannis Kosmidis ${ }^{2,3} \cdot$ Gianluca Baio $^{1}$. Mihai Cucuringu ${ }^{3,4} \cdot$ Gavin Whitaker ${ }^{1}$. Franz Király ${ }^{1,3}$}

Published online: 14 August 2018

(c) The Author(s) 2018

\section{Correction to: Machine Learning https://doi.org/10.1007/s10994-018-5741-1}

The Publisher regrets an error in the presentation of Table 5. The corrected table is provided below.

Table 5 Ranked probability score and classification accuracy for the models in Table 4, as estimated from the validation framework of Section 5 (standard errors are in parentheses) and from the matches in the test set of the challenge

\begin{tabular}{|c|c|c|c|c|c|c|c|c|}
\hline \multirow{2}{*}{\multicolumn{2}{|c|}{ Model }} & \multirow[b]{2}{*}{ Draws } & \multicolumn{3}{|c|}{ Ranked probability score } & \multicolumn{3}{|c|}{ Accuracy } \\
\hline & & & \multicolumn{2}{|c|}{ Validation } & \multirow{2}{*}{$\begin{array}{l}\text { Test } \\
0.2261\end{array}$} & \multicolumn{2}{|c|}{ Validation } & \multirow{2}{*}{$\frac{\text { Test }}{0.4515}$} \\
\hline & BL & Davidson & 0.2242 & $(0.0024)$ & & 0.4472 & $(0.0067)$ & \\
\hline & $\mathrm{BL}$ & Ordinal & 0.2242 & $(0.0024)$ & 0.2261 & 0.4472 & $(0.0067)$ & 0.4515 \\
\hline & $\mathrm{CS}$ & Davidson & 0.2112 & $(0.0028)$ & 0.2128 & 0.4829 & $(0.0073)$ & 0.5194 \\
\hline & $\mathrm{CS}$ & Ordinal & 0.2114 & $(0.0028)$ & 0.2129 & 0.4779 & $(0.0074)$ & 0.4951 \\
\hline & LF & Davidson & 0.2088 & $(0.0026)$ & 0.2080 & 0.4849 & $(0.0068)$ & 0.5049 \\
\hline & LF & Ordinal & 0.2088 & $(0.0026)$ & 0.2084 & 0.4847 & $(0.0068)$ & 0.5146 \\
\hline & TVC & Davidson & 0.2081 & $(0.0026)$ & 0.2080 & 0.4898 & $(0.0068)$ & 0.5049 \\
\hline & TVC & Ordinal & 0.2083 & $(0.0025)$ & 0.2080 & 0.4860 & $(0.0068)$ & 0.5097 \\
\hline & AFD & Ordinal & 0.2079 & $(0.0026)$ & 0.2061 & 0.4837 & $(0.0068)$ & 0.5194 \\
\hline$\star$ & HPL & & 0.2073 & $(0.0025)$ & 0.2047 & 0.4832 & $(0.0067)$ & 0.5485 \\
\hline$\dagger$ & TVC & Ordinal & 0.2085 & $(0.0025)$ & 0.2087 & 0.4865 & $(0.0068)$ & 0.5388 \\
\hline
\end{tabular}

The model indicated by $\dagger$ is the one we used to compute the probabilities for the submission to the MLS challenge, while the one indicated by $\star$ is the one that achieves the lowest estimated ranked probability score

The original article can be found online at https://doi.org/10.1007/s10994-018-5741-1.

\footnotetext{
$凶 \quad$ Alkeos Tsokos

alkeos.tsokos.10@ucl.ac.uk

1 University College London, London, UK

2 University of Warwick, Coventry, UK

3 The Alan Turing Institute, London, UK

4 University of Oxford, Oxford, UK
} 
Publisher's Note Springer Nature remains neutral with regard to jurisdictional claims in published maps and institutional affiliations. 